Revista Iberoamericana, Vol.LXXV, Núm. 228, Julio-Septiembre 2009, 605-636

\title{
INTRODUCCIÓN: CONFLUENCIAS DE LO TRANSATLÁNTICO Y LO LATINOAMERICANO*
}

\author{
POR

$\begin{array}{lrl}\text { Eyda M. MEREDIZ } & \text { Y } & \text { Nina Gerassi-NaVARRO } \\ \text { University of Maryland, } & \text { Tufts University }\end{array}$

College Park

El auge de los llamados “estudios transatlánticos” como acercamiento crítico dentro de la academia norteamericana y centros interdisciplinarios noreuropeos ha generado intensos debates sobre la delimitación de este campo, su metodología, su viabilidad y sus aplicaciones más allá de las disciplinas establecidas o las áreas de estudio tradicionales. Para cualquier aproximación al desarrollo más reciente de los mismos, es necesario sin embargo explorar el proceso por el cual el Atlántico se vuelve el protagonista fundamental en escuelas críticas que privilegian nociones de espacio y geopolítica y dan origen tanto a la "Historia Atlántica" como a los "Estudios Atlánticos o Transatlánticos”, hoy en día utilizados casi indistintamente. ${ }^{1}$ La primera está más apegada a la disciplina de la historia, con una genealogía más diáfana; los otros son más comunes dentro de la crítica cultural-literaria y resisten una taxonomía fácil aunque siempre presuponen una travesía o un cruce. Con los ensayos que presentamos en este volumen, nos interesa evaluar cómo estas articulaciones pueden impactar o interrelacionarse con los modos y maneras en que se estudia Latinoamérica como espacio geopolítico.

CONTEXTUALIZACIÓN DEL ESPACIO Y DE LA HISTORIA ATLÁNTICA

El mundo Atlántico no sólo está atado a la exploración empírica y gradual del océano que le da su nombre, sino también a una serie de descubrimientos científicos

* El minucioso trabajo de edición e intensas horas de discusión académica y gramatical a cargo de María Verónica Muñoz han sido indispensables para sacar adelante este volumen. Le agradecemos además su inteligencia, paciencia y dedicación. Gracias también a Silvia Bermúdez, Joseba Gabilondo, Izáscum Álvarez Cuartero y Ana Lau por sus valiosas sugerencias.

1 Para evitar las asociaciones semánticas que los términos “trasatlántico/a” o “atlantismo" evocan en el uso de la lengua española, ya sea relacionadas al transporte marítimo o a la adhesión a los principios de la OTAN (RAE), adoptamos “transatlántico/a” y “atlanticismo" que reflejan una resemantización tal como se plantea en los nuevos debates de la crítica literaria y cultural. 
y al tráfico de seres humanos, artefactos e ideas que repercuten más allá de su geografía obligada, que por último los reterritorializan en una cultura mundial o global. Si bien tanto los descubrimientos como los imperios que nacen en el contacto con el Atlántico se fundan sobre presupuestos eurocéntricos y nororientados, en las últimas décadas del siglo xx los procesos de descolonización y los acercamientos críticos del posestructuralismo, el poscolonialismo y las perspectivas globalizadoras los han puesto en crisis. Sin embargo, es el Atlántico como entidad conocible el que ha servido de objeto de investigación a la "Historia Atlántica" articulada a partir de la Segunda Guerra Mundial, el que sella la relación entre Estados Unidos y Europa, y que, al mismo tiempo, funciona como mecanismo excluyente de otras relaciones atlánticas que gradualmente se ha buscado corregir.

Un buen punto de partida para nuestro sondeo es el número especial de la Revista de Occidente (2004) dedicado al tema de la historia atlántica, que comienza con un trabajo traducido del historiador británico David Armitage. ${ }^{2}$ Según Armitage, la historia es la disciplina que con "más seriedad y entusiasmo" ha adoptado la perspectiva atlántica (7). Armitage acude a la obra de Bernard Bailyn, que a partir de la década de 1950 se convierte en el promotor oficial de esta historia y ha construido su genealogía recientemente (véase también Steele 48). ${ }^{3}$ La historia atlántica se inicia así en un marco de compromiso internacional y búsqueda de valores comunes, asentado sobre una historia similar "que vinculaba las sociedades norteamericanas con Europa a través de un conjunto compartido de valores pluralistas, democráticos y liberales”, pero también religiosos de base judeocristiana (Armitage 10). De esta manera, se hace evidente que la historia atlántica nace con considerable retraso a la "invención europea del Océano Atlántico" (8-9). Por otro lado, el controvertido tema de la raza, el tráfico de esclavos, y la relación con África y con los africanos, quedan excluidos en esta suerte de "Atlántico Blanco" enraizado en la guerra fría y que no permite recuperarlos hasta mucho después. Posicionándose en un lugar de cruce entre lo británico y lo norteamericano, Armitage proporciona una genealogía

2 Ya desde 1996, en la Universidad de Harvard se llevan a cabo seminarios sobre historia atlántica y Armitage está afiliado a esta universidad desde el 2004.

3 Tanto Armitage (11) como Federica Morelli y Alejandro E. Gómez, en sus evaluaciones bibliográficas del tema, insisten en que la historiografía de posguerra es el catalizador para el estudio del Atlántico, sus sistemas y revoluciones como antesala al despliegue del concepto de "civilización" por ende “occidental”. Se destacan entonces los trabajos de Robert Palmer (1959) y Jacques Godechot (1947), los de Huguette y Pierre Chaunu (1955-1959), al igual que los de Charles Verlinden, todos historiadores europeos a los que Steele atribuye bases empíricas muy sólidas, aunque recibieron el rechazo y la resistencia, no sólo de nacionalistas diversos, sino de los que pensaban que la perspectiva atlántica a la que se adscribían servía únicamente a los intereses norteamericanos durante la guerra fría (49).

4 El trabajo de Armitage ha sido traducido al español pero se puede ya encontrar una bibliografía considerable que construye genealogías parciales y generales, entre las que se destaca la de William O’Reilly. 
y una anatomía de la historia atlántica, catalogándola en tres tipos fundamentales: la circunatlántica, la transatlántica y la cisatlántica. ${ }^{4}$ La primera incluye el contorno de todo el océano y sus costas, la segunda compara los vínculos entre naciones y estados dentro de la zona atlántica y la tercera establece el valor de lo regional que cuenta la historia de comunidades específicas en su relación con el intercambio atlántico y como interlocutor válido de un diálogo con Europa.

Acuñado por el historiador del teatro norteamericano Joseph Roach (1996), el término circunatlántico le sirve a Armitage para explicar una historia oceánica y transnacional que parte de la concepción del Mediterráneo en la época de Felipe II propuesta por Fernand Braudel, pero que a la vez no se explica a través de su determinismo geográfico (Armitage 15-16). ${ }^{5}$ No es accidental tampoco que, sobre las bases sentadas por Braudel, Immanuel Wallerstein haya elaborado la teoría del sistema mundo (world-system). A partir de las historias del Atlántico Negro, sin embargo, se ha abandonado la visión integradora, lineal y teleológica del Atlántico Blanco por el énfasis en la circulación y la fluidez (13-16) que tanto Paul Gilroy, desde la sociología e historia cultural, como James Clifford, desde la antropología, han articulado acertadamente.

La historia atlántica puede ser también transatlántica e internacional; términos que empiezan a usarse en la lengua inglesa durante la guerra de independencia norteamericana el primero, y en los escritos de Jeremy Bentham el segundo (1718). De hecho, es una historia comparada que asume la existencia de naciones y estados, concentrada por lo general en un "eje que atraviesa el mundo atlántico de norte a sur”, por lo que, según Armitage, ha sido más interimperial que internacional (17-19). Ello abre las posibilidades de un trabajo situado en el eje este-oeste que, según el autor, ha sido menos explorado.

La historia cisatlántica o historia nacional y/o regional en un contexto atlántico, por su parte, apunta a lugares concretos que se definen "como el resultado de la interacción entre la especificidad local y una red de conexiones más amplia” (20). El término cisatlántico ya es usado por Thomas Jefferson a fines del siglo XVIII para remarcar la especificidad local de la fauna norteamericana, más allá de su contraparte europea. Sin embargo, son los multivolúmenes de Huguette y Pierre Chaunu sobre Sevilla y el Atlántico, los que constituyen el ejemplo más fehaciente de esta modelación (21). Su valor radica en ayudar a desmantelar las fronteras artificiales de las historias que se construyeron en falsas oposiciones como "internas y externas, locales y foráneas o nacionales e imperiales” (22).

\footnotetext{
5 Heidi Slettedahl Macpherson y Will Kaufman en su introducción a New Perspectives in Transatlantic Studies apuntan que, además de los estudios de Roach (1996) sobre Performance circunatlántica y de Gilroy (1993) sobre el Atlántico negro, el trabajo de Marcus Rediker, Between the Devil and the Deep Blue Sea (1987), sobre la piratería en el siglo xviII ya trasciende los perímetros de la nación británica y las naciones americanas, inaugurando otra manera de cuestionar el Atlántico (xiv-xv).
} 
Esta trifurcación inscribe la dimensión triple de una misma historia atlántica que al ser abordada desde lo transnacional, lo internacional y lo nacional se reúne geográficamente, se abre a comparaciones o se fija, desde un locus particular, en las múltiples afluencias que la circulan. A pesar de que la categorización de Armitage resulta útil, la evaluación crítica de Ian K. Steele la complementa al demostrar que el Atlántico de Bailyn es selectivo y su genealogía particular parte de la primera guerra mundial, cuando Estados Unidos decide salir de su aislamiento (49). Steele trae a colación lo que en las genealogías históricas que se montan alrededor de una perspectiva atlántica con frecuencia se deja a un lado: la contribución de la historiografía en torno a una temprana modernidad menos monolítica. También proporciona una bibliografía sobre los imperios ibéricos o del mundo mediterráneo (49), apuntando que el propio Bailyn cataloga de irrelevante para su propuesta la influencia del historiador francés Fernand Braudel(51). El aparente foco internacional de Bailyn juega deliberadamente con lo americano, o sea lo estadounidense, alimentando así el "excepcionalismo norteamericano" (53). Steele, sin embargo, reconoce que los postulados de Bailyn son cada vez más atractivos para la práctica de una historia atlántica que se abre, sin cambiar de archivos ni de idiomas ni de trasfondo ideológico, a una multiplicidad de caminos menos excluyentes (58). Esta historia auspicia una serie de posibilidades para el Atlántico, el Negro, el Blanco, el Rojo, e inclusive el Verde-irlandés (56n15). ${ }^{6}$ Nuestro interés es precisamente explorar las bases de otro Atlántico, el hispano y latinoamericano, que tiene también una genealogía propia y que, al mismo tiempo, se entrelaza con las anteriores, sin dejar de lado sus lazos con toda la tradición de los estudios coloniales y con una temprana modernidad imperial particularmente ibérica, sabiendo de antemano toda la complejidad que esto implica.

Según Luís Adão da Fonseca, el conocimiento del Atlántico, su cartografía y exploración, desarrollados fundamentalmente a partir del siglo xv con las navegaciones portuguesas, hace que se transformen las nociones de espacio, lo que ocasiona una ruptura tanto con las concepciones clásicas como con la visión medieval del mismo. Al abrir la navegación del Mediterráneo al Atlántico, se rompe la noción antigua de que este océano es indistinto del Océano Índico o Etíope y se crea un modelo de economía unificada que primero se vierte hacia el Atlántico Norte y luego hacia el Sur (5-11). Marcada por la experiencia del viaje, se da así la transición desde una visión medieval, donde el espacio/lugar emanaba de las cosas y el Atlántico se asociaba con la verticalidad, con islas reales o imaginadas, redadas costales y viajes de circunvalación, a una percepción moderna del Atlántico fruto de la navegación astronómica, de una dimensión horizontal y una proyección total

\footnotetext{
6 Fundamentalmente, el Atlántico Blanco se asocia con los asentamientos europeos, el Rojo con las
} revoluciones y el Negro con la esclavitud (véase además el reciente estudio de Donna Gabbacia). 
hacia el sur, donde el espacio se empieza a pensar en términos de los cuerpos que lo ocupan (11-16). Los navegantes portugueses fueron artífices de la transformación de una geografía regida por "lugares" a otra dominada por la noción de "espacios" medibles y cuantificables (16-17). ${ }^{7}$

La vinculación del Atlántico con España y Portugal es precisamente el tema de otras dos contribuciones que aparecen en la ya mencionada Revista de Occidente, donde se revela cómo el conocimiento vertiginoso del Atlántico y las contiendas generadas en su entorno hacen de las monarquías ibéricas los primeros imperios globales. Sobre España y las Indias, Manuel Lucena Giraldo, que además organiza el número especial, explora cómo se constituye el poder imperial español en América y las formas en que dicho poder se articula y se negocia. Haciendo un recorrido desde los conquistadores y las tempranas instituciones coloniales hasta las reformas borbónicas y la caída del imperio, el historiador ofrece una descripción cronológica y de ella se desprenden algunos conceptos claves que fundamentalmente describen la mirada española hacia las Indias más que lo inverso. No explicita tampoco el nacimiento de la globalización occidental que sitúa a España en una modernidad atlántica derivada de su relación con América. Sobre Portugal y sus colonias, Rafael Valladares parte de la dificultad que presenta el imperio portugués para todo estudioso. Aunque reconoce la validez de una lectura atlántica que conecta a Portugal con Brasil y África, el historiador insiste en la necesidad de articularla conjuntamente con las colonias asiáticas donde se desplegó la corona portuguesa.

De estos dos trabajos, el de Valladares resulta más evaluativo sobre la aplicabilidad de la historia atlántica a la historia imperial portuguesa. No sólo cuestiona el tratamiento del imperio portugués dentro del continente europeo y su rol marginal en los estudios comparativos que se siguen sobre la Europa imperial (4546), sino que también propone la desnacionalización de la historiografía portuguesa y para ello reconoce la validez de pensar el ámbito luso como historia atlántica, con la salvedad de que el Atlántico no es el único espacio del imperio portugués puesto que su clave radica en su "constante cambio de centro de gravedad" (51). ${ }^{8}$ Sin embargo, la perspectiva atlanticista permite la triangulación y el flujo entre

7 Para medir el océano en aguas abiertas suelen utilizarse las coordenadas de latitud y longitud, aunque todavía hoy no hay un consenso general sobre sus límites. Uno de los problemas en el norte, por ejemplo, es que el océano Ártico suele considerarse dependiente del Atlántico por poseer una cuenca oceánica semi cerrada. Al sur, el límite por lo general se establece con el Cabo de Hornos y el pasaje de Drake (Encyclopaedia Britannica).

8 Valladares hace un rastreo bibliográfico abarcador y de suma utilidad, del que apenas seleccionamos unas pocas referencias. Vale la pena mencionar aquí la investigación científica de Charles R. Boxer que, como asegura Valladares, abre por primera vez "la construcción de una historia comparada de la colonización portuguesa comprensiva de todas sus áreas de expansión” (49). Además, varios historiadores que se ocupan de Brasil, se han volcado a los análisis atlánticos; véase por ejemplo los últimos trabajos de Stuart B. Schwartz. 
los espacios imperiales portugueses: Lisboa, los puertos esclavistas africanos, y las plantaciones y minas brasileras. Sin duda existió una civilización atlántica portuguesa "pero no sin que Oriente continuara vivo y, más importante aún, no sin que los flujos económicos y culturales provenientes de Asia continuaran influyendo en la dinámica atlántica” (57). Así se desmonta la posición de un Brasil atado a Lisboa y se abre un abanico de redes multifocales (57-58).

Valladares admite una renuencia de la historiografía lusa hacia la consideración de la historia atlántica, no sólo a causa de una herencia nacionalista o de la insuficiencia empírica, sino a causa del anclaje del mundo académico luso en el francés (43). La historia atlántica como formación anglonorteamericana se rechaza a favor de un modelo cercano a los Annales y a Braudel, como ilustra el estudio de Frédéric Mauro sobre Portugal, Brasil y el Atlántico (1960), aunque, más recientemente, el trabajo del brasileño Luiz Felipe de Alencastro (2000) sobre el Atlántico Sur exhibe una perspectiva atlanticista más compleja einterdependiente(53-54). La especificidad del mundo luso no es, sin embargo, únicamente atlántica, y se puede afirmar lo mismo para la América hispana que está en contacto con el comercio transpacífico. ${ }^{9} \mathrm{La}$ centralidad de Asia, no sólo en el caso de Portugal sino con respecto a toda Europa, ya ha sido enfatizada por el trabajo revisionista de André Gunder Frank, que tiene repercusiones drásticas para el eurocentrismo subyacente en la perspectiva de la historia atlántica y en la de los sistemas mundiales o globales.

En el caso de la historiografía sobre España y la América hispana conectadas entre sí y con Gran Bretaña y sus colonias, aún se requiere emprender una verdadera historia atlántica, según sostiene el historiador británico John H. Elliott, aunque reconoce que en algunos aspectos los historiadores del Atlántico hispano se han adelantado a sus homólogos británicos o angloamericanos al hacer conexiones entre las dos orillas. El propio Elliott ejemplifica una creciente apertura a la historia atlántica comparativa (2006). ${ }^{10} \mathrm{La}$ insuficiencia de perspectiva a la que alude el historiador refleja a su vez una tendencia europea, ya que la historia atlántica en Europa en general ha tenido un éxito limitado, como resumen Morelli y Gómez, y lo mismo se puede decir de Hispanoamérica, dada la carencia bibliográfica, de intercambios académicos o de grupos de investigación. Sin embargo, como indican las publicaciones, ya se ha comenzado paulatinamente a considerar viable esta categoría y sus definiciones, retos y oportunidades, no sólo como una etiqueta de moda.

La historiografía española tradicionalmente ha sido baluarte de un panorama intelectual que tiende a dividir el campo del saber entre el americanismo por un

\footnotetext{
9 Pierre Chaunu, para 1960, realiza además un trabajo minucioso sobre el Pacífico ibérico (Les Philippines).

10 Véase también el volumen editado por Nicholas Canny y Anthony Pagden en 1989.
} 
lado y la peninsularización o españolización por otro. Lo atlántico en sí estaba asociado con las islas atlánticas, en particular las Islas Canarias, y las costas africanas exploradas, saqueadas y disputadas fundamentalmente por los dos imperios ibéricos. El propio Braudel llamaba a la zona ocupada por las islas atlánticas de Madeira, Azores y Canarias el "Mediterráneo atlántico" (1: 134), y es indiscutible que su trabajo sobre lo que llamó las "Ilanuras líquidas" (1: 79) permitió que resaltara esta subzona. Y es precisamente en la época de la posguerra y de la incipiente historia atlántica del norte que nace el Anuario de Estudios Atlánticos, ${ }^{11}$ que funciona desde 1955 y, como su nombre lo indica, se ocupa no sólo de la historia sino de otras disciplinas. El Anuario hace de las Islas Canarias su centro de estudio, aunque se mueva con una óptica local nacionalista horizontal y verticalmente por otras islas, la costa africana, el Caribe y América. El apelativo "atlántico" sirve aquí para hablar de un espacio local, un entre-lugar, y para denominar lo que no cabe geográficamente en las áreas de estudio regionales establecidas, ya que no es ni peninsular ni americano. ${ }^{12}$

Los trabajos del historiador belga Charles Verlinden y los de los Chaunu en los años cincuenta, parte innegable de la genealogía de la nueva historia atlántica, lo son fundamentalmente para el Atlántico iberoamericano, y producen el tipo de interdisciplinariedad y apertura hacia el espacio geográfico-político-económicosocial del Atlántico que resulta revelador al retomar el posterior estudio de los imperios ibéricos y su expansión colonial. Felipe Fernández Armesto, por ejemplo, ha recorrido las posibilidades del Atlántico no sólo en su vertiente insular sino como camino hacia lo global; establece un contexto atlántico multiforme, rompe con la dicotomía definitoria que marca el antes y después de Colón y explora una dimensión global y fluida de la cultura atlántica (Before Columbus, The Canary, Millenium) ${ }^{13}$ Es entonces doblemente significativo que Elliott haya apelado por la búsqueda de una historia atlántica en la conferencia inaugural del XIV Coloquio de Historia Canario-Americana organizado por la Casa de Colón de Las Palmas de Gran Canaria en octubre de 2000. Precisamente en este espacio que ha habitado física y geopolíticamente la liminalidad, desde el Atlántico como entre-lugar o nolugar, se puede vislumbrar mejor otro Atlántico, el espacio que posibilita abarcar lo externo y lo nacional, descolocar causalidades y cruzar linealidades.

\footnotetext{
11 Véanse los números de la revista que han sido digitalizados hasta ahora en la red.

12 La metodología más tradicional de Antonio Rumeu de Armas, el editor más importante de esta revista, ejemplifica de qué manera, al utilizar el espacio insular de las Canarias como plataforma, se apela a relaciones más cruzadas (Piraterías y ataques [1947-50], España en el África atlántica [1956]).

${ }^{13}$ Fernández Armesto también participa en el dossier de la Revista de Occidente con un trabajo sobre el lenguaje que hablaban los esclavos. Actualmente, también dirige un seminario sobre historia global en la Universidad de Tufts que es parte de un consorcio mayor en la ciudad de Boston.
} 
Desde Latinoamérica, la figura de Edmundo O’Gorman se perfila como un historiador que entendió la dimensión atlántica de la colonización española de América y la imposición retórica de una geografía imaginada por un discurso colonial y poscolonial. Su historia es una historia atlántica de otro tipo. Ya desde 1937, en su Historia de las divisiones territoriales de México, O’Gorman se había enfocado en la dimensión espacial y territorial, aunque en el ámbito nacional. Más adelante, tanto La idea del descubrimiento de América (1951) como La invención de América. El universalismo de la cultura de Occidente (1958) se convierten en análisis pioneros de una tradición latinoamericana, como ha apuntado Walter Mignolo (“Colonial”), que desmonta quinientos años de historiografía occidental y de un universalismo construido desde Europa con una perspectiva única. Esto no implica que su acercamiento, como le criticó Miguel León Portilla en un debate público, tuviera en cuenta el mundo indígena americano que, en realidad, no figuraba en su línea ideológica. Aunque la década de los cincuenta es crucial para una incipiente historia atlántica, la de los noventa es determinante por su popularidad. Baste mencionar aquí que la nueva historia atlántica de nuestros tiempos ha producido trabajos ejemplares, como los de Jorge Cañizares Esguerra, que, desde la academia norteamericana, se acercan a una historia que subvierte todas las imposiciones del Atlántico Norte. En Puritan Conquistadors, por ejemplo, el historiador explora la persistencia de los modelos ibéricos en la colonización puritana de Nueva Inglaterra en lugar de considerarla una experiencia totalmente distinta, propinando así otro golpe al excepcionalismo estadounidense al mover la perspectiva histórica de análisis a un ángulo panamericano. En How to Write the History of the New World, reformula los debates que se dan en la historiografía española e hispana en torno al "Nuevo Mundo", localizando el origen de las sensibilidades modernas y posmodernas de crítica y análisis en el siglo XVIII. Siguiendo a críticos culturales, redefine la noción de modernidad y revisa las premisas que caracterizan el Barroco y la Ilustración en un estudio donde metrópolis y colonias son partes de un todo en constante interacción. Su metodología, por último, rompe con los paradigmas de progreso y modernización impuestos por el Atlántico Norte en todas las historias nacionales (How to Write $1-10) .^{14}$

${ }^{14}$ Cada vez se publican más historias comparativas, cruzadas y entrelazadas con el acercamiento globalizante que la nueva historia atlántica predica, sobre todo en Estados Unidos y Gran Bretaña. Véase también la reciente coedición de Cañizares Esguerra y Erik Seeman. En la academia española, se debe mencionar el trabajo del historiador José María Portillo Valdés, que ofrece una relectura de los conceptos de autonomía e independencia en el Atlántico Sur que trasciende todo encasillamiento disciplinario y nos presenta la historia de la crisis atlántica en la que España y Latinoamérica se involucran a partir de los albores del siglo diecinueve. El caso de Portillo no es único y, en la rama de la historia, cada vez se van formando más grupos de trabajo que buscan un enfoque atlántico más inclusivo (como el grupo de investigación de las independencias latinoamericanas en la Universidad de Salamanca, y otros en el CSIC). 
Alpresentarbrevementelos debates en tornoalahistoria atlánticanopretendemos abarcarlos en toda su complejidad ni ofrecer una bibliografía o genealogía completa, sino enfatizar que los mismos no atañen sólo a la transformación de la historia en su especificidad disciplinaria. De hecho, son también el fruto de un diálogo y de una mutua fertilización intelectual con una variedad de enfoques receptivos a otras disciplinas en pos de la ampliación del concepto de Atlántico como espacio complejo de interacciones. Las preocupaciones, los retos y las posibilidades que afloran de esta historia son también, en gran parte, las mismas y los mismos que informan los estudios transatlánticos culturales y literarios.

\section{LA EMERGENCIA DE LOS ESTUDIOS TRANSATLÁNTICOS Y EL LUGAR DE LATINOAMÉRICA}

Si bien a los llamados estudios transatlánticos (que incluyen otras variantes como los "Estudios Atlánticos” o la categoría del “Atlántico Hispano") se les pueden trazar diversas genealogías desde la historia o las ciencias sociales, los estudios literarios se hacen partícipes de ellos en la última década del siglo veinte y, fundamentalmente, en torno a la conflictiva fecha de 1992, en parte por lo que Julio Ortega ha catalogado como "el agotamiento de los modelos críticos dominantes" ("Presentación” 105). Aunque lo transatlántico busca romper con acercamientos teóricos asociados a escuelas de pensamiento específicas, es también resultado del auge de los estudios culturales y la historia cultural, terminología y metodologías escabrosas para la tradición latinoamericana cuya contribución a menudo se relega al margen o ha sufrido una sostenida penetración cultural desde afuera (véase Mabel Moraña, “Latin American Cultural Studies” 31-32), despertando el mismo tipo de sospechas y resistencias que ahora provocan los estudios transatlánticos, y que en su momento también provocaron el posmodernismo y los estudios poscoloniales. ${ }^{15}$ De ahí parten también las ansiedades de nombrar este campo de estudio, de buscar genealogías que apelen a una tradición hispana o latinoamericana o surorientada, y de integrarlos a los estudios latinoamericanos que cada vez más tienen un

\footnotetext{
${ }^{15}$ Sobre los estudios culturales y Latinoamérica, véase las recientes colecciones por un lado editadas por Ana del Sarto, Alicia Ríos y Abril Trigo y por otro por Catalina Castillón, Cristián Santibañez y Marc Zimmerman. Sobre el debate del posmodernismo, véase el volumen editado por John Beverley y José Oviedo. Con respecto a la crítica poscolonial, ver el debate que se da entre prominentes latinoamericanistas (Patricia Seed, Hernán Vidal, Walter Mignolo y Rolena Adorno) en LatinAmerican Research Review entre 1991-1993, el trabajo de Jorge de Klor de Alba y los volúmenes editados por Santiago Castro-Gómez y Eduardo Mendieta, al igual que el de Alfonso y Fernando del Toro. Véase también la colección editada por Robin Fiddian sobre Latinoamérica y el África de habla portuguesa. Esta serie de debates y consideraciones apuntan a su vez a otro debate crítico donde los estudios latinoamericanos en sí se han convertido en objeto de estudio (véase por ejemplo Román de la Campa).
} 
carácter transnacional y global. El reto se plantea en cómo trascender unos estudios transatlánticos que siempre se imaginan atrapados entre el expansionismo global español, la dominante academia norteamericana y la indiferencia latinoamericana. Aquí intentaremos armar un mapa de trabajos o postulados teóricos claves a los que se acude cuando se considera lo transatlántico en términos generales. Con la idea de establecer un mejor diálogo entre las diferentes posturas y conceptualizaciones de este campo híbrido y en desarrollo, haremos una evaluación de los rastreos temáticos y bibliográficos que se han hecho en los diferentes estudios introductorios de antologías, colecciones de ensayos y números especiales de revistas que hasta ahora han sido el foro más visible donde se le ha dado forma al campo de estudio en su relación a España y Latinoamérica (y en mucha menor escala a África).

La reciente década de los noventa inaugura la entrada de los estudios transatlánticos a la conciencia crítica de la academia norteamericana y europea, mientras que toma cuerpo la nueva historia atlántica y se propicia el auge de los análisis de sistemas globales en las ciencias sociales. ${ }^{16}$ La emergencia del Atlántico Negro de Paul Gilroy y su éxito general a través de las humanidades marcó un giro decisivo en el florecimiento de los estudios transatlánticos en el terreno de los estudios literarios-culturales. Gilroy llama la atención sobre otras localizaciones de la modernidad, sobre una modernidad alternativa, y sobre otros Atlánticos además del predominante Blanco-europeo. Las reflexiones de Gilroy surgen paralelas a las teorizaciones desde la antropología (James Clifford) sobre la cultura del viaje que se contrapone a una larga historia de privilegiar el asentamiento. Clifford enfatiza el movimiento, la travesía, las migraciones, el nomadismo y la circulación multidireccional. Los trabajos de Gilroy y Clifford están también a su vez en diálogo con las reconfiguraciones de la noción de espacio que desde la geografía (Edward Soja) han permeado y transformado numerosas prácticas disciplinarias. Los estudios transatlánticos parten entonces de un Atlántico que es, ante todo,

\footnotetext{
${ }^{16}$ Los volúmenes editados por Macpherson y Kaufman, derivados de las conferencias auspiciadas por el Centro de Estudios Transatlánticos de Maastricht en Holanda, a las que algunos de nosotros asistimos (Elvira Vilches, Eyda M. Merediz), se hacen eco de una crisis de los estudios de área que genera los estudios transatlánticos. Los encuentros evidenciaron cómo el campo predominante desde donde se articulaba lo transatlántico venía de lo Estudios Norteamericanos (American Studies); así lo reconocen los editores y se comprueba con la tenue presencia del Atlántico Sur. Reconocen además que lo transatlántico evoluciona de un espacio en creciente teorización y que comparte su posición con otros términos y conceptos como el circunatlanticismo, el transnacionalismo, el internacionalismo y la globalización (New Perspectives xiv). Al respecto, el trabajo de Sophia McClennen se pregunta si el giro hacia los estudios interamericanos (que vemos como resultado de los transatlánticos) es una manifestación más del imperialismo que ejercen los estudios norteamericanos, concluyendo que las posibilidades para producir nuevos estudios transculturales más allá de fronteras geográficas o identitarias superan la amenaza imperialista.
} 
un espacio geopolítico que genera sus propias estructuras de poder, por lo que la conexión entre el imperialismo y la modernidad, como apunta Joseba Gabilondo, es su preocupación predominante (“A Multicultural” 45-46n2).

La geografía cultural con sus articulaciones geopolíticas es por lo tanto más importante para la teorización de los estudios transatlánticos de lo que se ha recalcado y resulta una noción fundamental para la óptica que guía nuestra selección de trabajos para este volumen. La reconceptualización del espacio, ya no como algo fijo y definido, sino como una construcción social y política, y por ende mucho más permeable y compleja, ha dado una nueva dimensión al estudio del Atlántico. En su ya clásico estudio La producción del espacio, Henri Lefebvre parte de la diferencia entre la producción y la administración del espacio para diferenciar el espacio vivido del percibido y del concebido (53). Esta triangulación espacial es fundamental para la reformulación conceptual del espacio porque despliega los diferentes tipos de poderes implícitos en su construcción y sus relaciones con el poder hegemónico. El espacio no puede pensarse fuera de una práctica social, de forma "neutral" (292); al ser vivido, en él se inscriben los cambios sociales, de conocimiento y de instituciones. Así, el espacio se vuelve un instrumento fundamental para el análisis de la cultura. Si bien el trabajo de Lefebvre se enfoca principalmente en el espacio urbano, su planteo es útil para los estudios culturales en general porque subraya el proceso de construcción social del espacio (urbano o no) y su relación con la representación (tanto el espacio de la representación como la representación del espacio). Edward Said, por su parte, subraya la importancia de entender el espacio como una construcción para poder desarticular el eurocentrismo hegemónico (y el poder que éste conlleva) que se impone a las culturas otras (Orientalism). Lo radical del pensamiento de Said fue el quebrar la noción de fronteras universales al dislocar el pensamiento epistemológico occidental y relativizarlo ante una historia y localidad específica. En la era de la poscolonialidad es indispensable revisar nuestra noción de la geografía y entender cómo se interrelacionan espacio, poder y conocimiento si es que queremos habilitar nuevas representaciones de la cultura.

Asílo haceEdward Soja, quien retoma la triangulación en Tercer espacio (1996), donde propone diferentes modos de pensar "el sentido y significado del espacio" en la cultura, propuesta que ya había iniciado en Geografías posmodernas (1989). Soja ve la triangulación, o trialéctica, como una forma de superar las categorías binarias y promover un análisis de la cultura que va "más allá de lo otro", es decir impedir el razonamiento dialéctico y totalizador para abrir el pensamiento a múltiples “otredades”. En su análisis, rastrea los aportes de numerosos teóricos, entre ellos Said, bell hooks, Gayatri Spivak y Michel Foucault, por ser quienes han pensado críticamente acerca del espacio y la espacialidad humana desde diferentes posiciones (155). Soja recalca que la multiplicidad y la heterogeneidad espacial de 
la otredad, que él denomina tercer espacio, no debe constreñirse a una especie de trinidad, porque el objetivo es seguir expandiendo la producción de conocimiento, no congelarla (61).

Estos enfoques recientes en torno al tema ponen en evidencia que la categoría espacio, por ende también el Atlántico, había sido históricamente relegada a un segundo plano en relación al tiempo, y que en realidad no debería estar escindida una de la otra. Ya Michel de Certeau, y especialmente Michel Foucault, trascienden esta división de tiempo y espacio, introduciendo el concepto de heterotopías, espacios heterogéneos, interrelacionados e irreducibles (Foucault 23). La compleja relación entre espacio y tiempo continúa siendo discutida hoy y resulta fundamental tener presente este debate a la hora de situarnos en el espacio atlántico y las posibilidades de un estudio inclusivo de lo que lo constituya. Un ejemplo interesante es la perspectiva de Doreen Massey, que en su libro más reciente, For Space, reexamina el espacio, reflexionando acerca de los relatos de la conquista donde éste es imaginado como una superficie, un lugar que se cruza, se ocupa, se apropia. Según Massey, nuestra mirada da prioridad al que viaja, al conquistador, que recorre mar y tierra, y posee el territorio. Medimos los hechos en función al movimiento y de quien lo realiza. Irritada por el excesivo exclusivismo de lo local y preocupada por las inequidades (económicas, culturales, de género) que impone la hegemonía de la gobalización, Massey se propone repensar la categoría del espacio y su vínculo con el tiempo como resistencia política al poder hegemónico (6). Para ella, una de las claves de esta reconceptualización está en la representación (visual, lingüística, temporal), por lo que insiste en que el espacio y el tiempo están ligados y aboga por la apertura de ambos. No es que sean iguales, explica: "son integrales el uno al otro" (47). Al unificarlos, reconociendo sus diferencias, desarticula jerarquías y abre la posibilidad de nuevas topografías, acto que constituye su postura política.

Desde otro enfoque, los estudios poscoloniales y los de subalternidad también enfatizan que, más allá de heteronimias y pluralidades de espacios y tiempos, el espacio también es un elemento o una coordenada histórica y social que permite la ocultación, la represión y el desplazamiento de voces, sujetos y lugares que pasan a ser invisibles o no representados. Por último, los estudios de la globalización y la posmodernidad son los que principalmente, $\mathrm{y}$ en muchos casos desde discursos hegemónicos, han convertido de nuevo en el vector central de todo discurso cultural al espacio que la filosofía europea moderna (el vitalismo y el existencialismo) había desestimado.

Estas perspectivas en torno a una espacialidad compleja, atravesada por sujetos, objetos, hegemonías y fuerzas múltiples, son la base, a grandes rasgos, de los estudios transatlánticos que, sin dejar de ser influyentes, se perciben como foráneos, estériles o tangenciales para la tradición teórica hispana o latinoamericana, que han tenido 
otro desarrollo en parte paralelo a los mismos. De ahí que hagamos hincapié en el Atlántico Sur, los modelos imperiales ibéricos, la experiencia colonial compleja de Latinoamérica y las teorías que se generan en un conocimiento de primera mano de sus realidades.

A diferencia de muchos de los volúmenes que agrupan estudios transatlánticos y que por lo regular se ocupan de lo moderno o contemporáneo, el nuestro busca incluir los estudios sobre el Atlántico que se vinculan tradicionalmente con el perído colonial y los movimientos que se han dado en este espacio oceánico desde 1492. Si bien se reconoce la fecha de celebración del Quinto Centenario como un hito que permitió revisitar las relaciones entre España y América (véase Pérez de Mendiola por ejemplo), pocas veces se incluye lo colonial en la selección de trabajos o en la teorización al respecto, ya que la transformación que ocurre en el campo de los estudios coloniales a partir de la década de 1970 hace que el trabajo de muchos sea transatlántico antes de que se acuñara la práctica, no sólo por la naturaleza del objeto de estudio sino por su inclusividad. ${ }^{17}$ Esto se admite y se pasa por alto porque el gesto trasatlántico que se potencia es el que busca comparaciones, influencias, cruces y travesías después de la fragmentación nacionalista del saber, en la era de todos los pos, donde a la colonia se la trata como legado o se la asume como obviamente transatlántica. ${ }^{18}$

Una genealogía que no ponga a los estudiosos de la Latinoamérica colonial al frente de una práctica transatlántica avant la lettre y desde diferentes localizaciones sería incompleta. Es un campo donde con las contribuciones del saber indígena y las prácticas de la territorialización, el coloniaje, las negociaciones de lo que Walter Mignolo ha llamado "semiosis colonial" ("Colonial”, Darker Side, Local Histories 14-16) no sólo se deconstruyó la historiografía occidental, sino que se cambió el paradigma de la historia literaria y se teorizó una modernidad asociada con Latinoamérica. Ya en la década de los ochenta, fundamentalmente Rolena Adorno, entre otros, había abogado por una práctica crítica transatlántica en el marco de

\footnotetext{
17 La fecha de 1992 es clave para este rastreo pero hay que mencionar además que ya para 1997 aparecen en la lista de trabajos de Modern Language Association of America (MLA) posiciones que buscan lo atlántico o transatlántico y que han ido aumentando con los años. Muchos latinoamericanistas e hispanistas de la academia norteamericana, a diferencia de los de la canadiense y la británica, están en conflicto con los estudios transatlánticos, que son vistos, no sólo como una estrategia administrativa para recortar personal especializado y recursos o fusionar programas, sino como otro catalizador que alimenta la tensión colonial existente entre los estudios peninsulares y latinoamericanos. Así se ha expresado en diversos paneles organizados para conferencias multitudinarias como las de MLA o las de Latin American Studies Association (LASA).

${ }^{18}$ Véanse por ejemplo las introducciones y la selección de artículos en las revistas o antologías editadas por Julio Ortega, Marina Pérez de Mendiola, y Francisco Fernández de Alba y Pedro Pérez del Solar.
} 
los estudios coloniales y en respuesta a los juicios culturales y nacionalistas que se habían impuesto sobre el corpus colonial. A esto, se ha añadido en los noventa el estudio comparativo de diferentes experiencias coloniales, especialmente en el eje norte-sur (Ralph Bauer) o comparaciones imperiales (Barbara Fuchs, Lisa Voigt). Sin embargo, el trabajo filosófico de Enrique Dussel y el de Walter Mignolo desde la crítica literaria-cultural resulta fundamental porque, al situar la modernidad en el Atlántico y en la colonización de América, ambos han denunciado la inscripción de valores falsamente universales desde Europa o América del Norte. De hecho, es la categoría de espacio la que sirve de plataforma a Mignolo para pensar la complejidad del mundo colonial, y la ve como noción abarcadora que integra lengua, memoria y tiempo (Darker Side xv). ${ }^{19}$

Esto no quiere decir que lo transatlántico, como se practica actualmente, haya sido recibido cálidamente en la crítica latinoamericana colonial. Por el contrario, su insistencia en una temprana modernidad que neutralice la especificidad latinoamericana apunta a limitaciones que los trabajos de Yolanda Martínez-San Miguel, por ejemplo, se encargan de exponer. Martínez-San Miguel sostiene que en todo acercamiento transatlántico a las categorías de modernidad e imperialismo hay que sumar la noción de colonialidad (definida por Mignolo y Aníbal Quijano), y sólo así se puede reconsiderar la posición periférica de la América colonial en el milieu cultural, epistemológico y político de la temprana modernidad ("Colonial No More”, From Lack to Excess). ${ }^{20}$

Si la práctica de estudios trasatlánticos comparados, entrelazados e inclusivos con respecto al género y a la presencia africana en las Américas empieza a dominar la investigación de la temprana modernidad, también ha dejado su marca en las investigaciones de la modernidad. Son varios los volúmenes y los proyectos de trabajo conjuntos que se han dado a la tarea de repensar las relaciones transatlánticas entre la península ibérica y Latinoamérica.

\footnotetext{
19 No sólo el trabajo de Edmundo O’Gorman sino el de Ángel Rama sobre la ciudad es fundamental para una genealogía temprana de la crítica cultural-filosófica latinoamericana donde el espacio aflora como categoría primordial. El trabajo de Mary Louise Pratt sobre lo que llamaría "zonas de contacto” es un exponente de estas tendencias, además del importante aporte de Mignolo. Véase la introducción y antología de trabajos en el volumen editado por Santa Arias y Mariselle Meléndez sobre espacio y poder colonial.

${ }^{20}$ El auge de esta perspectiva atlántica ha generado una verdadera apoteosis de estudios comparativos de la temprana modernidad desde ángulos diversos. Para una bibliografía bastante completa del asunto hasta el momento, véase la introducción de Daniella Kostroun y Lisa Vollendorf a una colección -que está por aparecer- de ensayos que buscan ampliar los estudios atlánticos y expandir la rúbrica de comunidad atlántica al privilegiar los asuntos de género y religión con una metodología derivada de la historia, los estudios literarios y la antropología (Women and Religion in the Atlantic World [1600-1800]).
} 
Los reclamos que se hacen a las prácticas teóricas de la academia norteamericana y al enclaustramiento de la academia española son la base de la formulación de los estudios transatlánticos a los que aspira Julio Ortega, cuyos ensayos y grupos de trabajo desde la Universidad de Brown son uno de los principales exponentes prescriptivos de un tipo de "estudios transatlánticos" como la alternativa más aceptable en la era de la posteoría. Ortega discute las vertientes críticas que llevan a un "escenario posteórico" que supere lo poscolonial, donde se da el escenario idóneo para acercamientos "supra históricos", creativos y abiertos que permitan trascender las genealogías disciplinarias y las posiciones o identidades fijas del sujeto. Su postura toma en cuenta el desarrollo de una perspectiva latinoamericana de los estudios culturales o de crítica cultural donde nacen "prácticas críticas en tensión con los modelos de Archivo académico" y que terminan por "evidenciar los límites disciplinarios”. Ortega parte además de una noción de modernidad que es incomprensible sin el aporte de Latinoamérica. Para él, los estudios transatlánticos se definen como una exploración transdisciplinaria en constante proceso, de diálogo abierto, donde se potencian articulaciones menos regidas por hipótesis y autoridades teóricas anquilosadas o institucionalizadas. El discurso de lo transatlántico "se mueve entre islas que rehacen la nominación y costas que exceden la catalogación” (“Posteoría” 114).

Los postulados de Ortega, de los que se hacen eco Francisco Fernández de Alba y Pedro Pérez del Solar, ofrecen un panorama alentador para los estudios transatlánticos. Rechazando la idea de que es una categoría donde cabe todo, donde lo viejo se disfraza de nuevo, presentan los estudios transatlánticos como una "nueva conceptualización de la crítica literaria, la historia y la sociedad de las culturas hispanas en la Península o en las Américas” (99). En este dossier coordinado en el 2006, de Alba y Pérez del Solar hacen un esquema útil del lugar de los estudios transatlánticos en la crítica cultural hispanoamericana y en los cambios curriculares y administrativos que se dan en las universidades norteamericanas (100). En realidad, amplían el horizonte temático de Ortega ("la re-escritura del momento colonial, la hibridez en la traducción, el tránsito de los exiliados, y la vanguardia histórica”) para incluir muchas otras posibilidades más allá de la literatura (105). Por ello, sostienen que la crítica literaria española, aislada y provincialista, sería la mayor beneficiada de los acercamientos transatlánticos mientras la latinoamericana puede hacer una transición natural hacia los mismos dada su larga trayectoria creativa y excepcional en la teoría cultural (la transculturación de Fernando Ortiz, la heterogeneidad de Antonio Cornejo Polar o la hibridez de Néstor García Canclini) (101). Si bien el hispanismo en todas sus vertientes necesita ser revisado (y el volumen sobre las ideologías del hispanismo editado por Mabel Moraña lo hace), también lo han hecho, desde Estados Unidos, una serie de críticos cuyo trabajo intelectual está ligado a la 
península ibérica y que no se incluyen en esta discusión, como por ejemplo Silvia Bermúdez, Jaume Martí Olivella, Sebastiaan Faber, Joseba Gabilondo y Jill Robbins, entre otros. En el mismo espíritu crítico, tenemos que considerar los límites del excepcionalismo latinoamericano y su relación sutil con el eurocentrismo. ${ }^{21}$

Volúmenes como los anteriores son complementados por otros de simultánea o reciente aparición, cuyas introducciones buscan matizar las relaciones complejas que se generan en el Atlántico Hispano. Éste es el caso de Marina Pérez de Mendiola, que propone un tipo de diálogo del que deben participar los estudios transatlánticos, y que ofrece una genealogía a partir de grupos de trabajo, instituciones, centros, conferencias y debates, ahondando en la literatura y en los estudios culturales comparados (2006). ${ }^{22}$ El diálogo fundamental que se busca aquí es con el transatlanticismo que se ha venido practicando en Estados Unidos y en Europa

${ }^{21}$ Véase la propuesta de Joshua Lund al respecto y también la reciente antología sobre Colonialidad y crítica en América Latina editada por Carlos A. Jáuregui y Mabel Moraña, en cuya introducción, los editores rechazan la noción de "excepcionalismo" en favor de la "diferencia americana" (14).

${ }^{22}$ Ya Pérez de Mendiola, desde la literatura peninsular y comparada, inauguró un diálogo transatlántico entre España y Latinoamérica con una temprana antología de ensayos en 1996 que se enfrascó en la búsqueda de un lenguaje común. Sin embargo, es en su más reciente volumen en que destaca una lista de iniciativas intelectuales que vale la pena repasar y que deriva en parte de un artículo de Barbara Buchenau y Marietta Messmer. Además del Centro de Estudios Transatlánticos de Maastricht (Holanda), se añade la "Sección Interamericana” del Centro para el estudio del carácter internacional de las literaturas nacionales de la Universidad de Göttingen (Alemania) y el Proyecto Transatlántico de la Universidad de Brown (Estados Unidos), que surgen en 1997 con el fin de propiciar una perspectiva intercultural sobre las literaturas americanas a partir de un diálogo entre Europa, Latinoamérica y los Estados Unidos, al igual que un proyecto de historias literarias comparativas con base en la Universidad de Toronto (4). Pérez de Mendiola señala también proyectos posteriores y publicaciones como The Journal of Transatlantic Studies de Edimburgo (Escocia), y la creación de la Asociación de estudios transatlánticos en 2002, al igual que la Red de Estudios Transatlánticos, de información electrónica, que expresan el creciente entusiasmo de los académicos por este campo en formación (4-5). Más recientemente, en 2004, se fundó la revista Atlantic Studies: Literary, Cultural and Historical Perspectives on Europe, Africa, and the Americas, y hay universidades que ofrecen maestrías en estudios culturales transatlánticos, donde se estudian conjuntamente las tradiciones literaria y visual de España y Latinoamérica (la Universidad Estatal de Illinois, por ejemplo). Otras universidades, como la de Duke y la de Michigan, se han volcado en iniciativas atlánticas de corte interdisciplinario. El Atlántico, en su vertiente ibérica, se ha convertido en objeto de estudio en la Universidad de Liverpool, que ya ha organizado dos conferencias importantes, la primera para repensar el Atlántico ibérico y la otra centrada en ir más allá de la esclavitud. A esto se suma otro grupo de trabajo en la Universidad de Essex sobre los trópicos americanos de corte más hemisférico. Actualmente, también, se están formando grupos de trabajo con este enfoque tanto en Estados Unidos como en Canadá, que reciben financiación de entidades científicas, por ejemplo un equipo de investigadores del Grupo de Investigaciones Transatlánticas, bajo la dirección de Juan Luis Suárez (La Universidad del Oeste de Ontario en London, Canadá), ha obtenido del Consejo de Investigación de Humanidades y Ciencias Sociales (SSHRC/CRSH) una subvención de 2,5 millones de dólares por su proyecto: “The Hispanic Baroque: Complexity in the First Atlantic Culture” (véanse los detalles en la dirección oficial http://www.hispanicbaroque.ca). 
del Norte (Alemania, Inglaterra, Holanda, etc.), y que en menor o mayor grado incluye a Iberia y Latinoamérica. Pérez Mendiola asevera además que las relaciones culturales entre Europa y América permiten diversas perspectivas teóricas, como el paradigma posteórico que asume Julio Ortega, que en parte reacciona a los estudios poscoloniales y a su victimización del sujeto. Pérez de Mendiola acertadamente corrige esta posición reduccionista al alegar que los estudios transatlánticos no son todavía el lugar donde la marginalidad del sujeto pueda minimizarse (5). Reconoce también que la exploración de las relaciones transatlánticas, independientemente de cuán productivas sean en la era de la posteoría, continúan inscritas dentro de parámetros que reproducen imposiciones coloniales, imperiales y patriarcales. Propone entonces desmontar las nociones de "tradición común" e "hispanismo" para que críticos de ambos lados del Atlántico se encuentren unos con otros en diálogo (6).

Para romper y vivificar esta tradición que se describe con la imagen derridiana de una herencia esclerotizada y de repetición ritual, se apela a los estudios transatlánticos y a las posibilidades de otro tipo de diálogo (7). Siguiendo el pensamiento de Emmanuel Lévinas, Pérez de Mendiola propone una ética del diálogo que no se articule dentro del universo propio sino que exija una apertura hacia la otredad, imposible desde la tradición común (7). Para propiciar el encuentro desde el diálogo, Pérez de Mendiola afirma que es necesario desoír a la tradición, situarse fuera de ella, y examinar esa reciprocidad segura que la define para desarrollar una (auto) crítica que la socave (7). Al releer el hispanismo desde Jacques Derrida y el diálogo desde Lévinas, se crea el mismo efecto que se le critica a la posición posteórica, el de disolver las relaciones de poder. En la posteoría de Ortega no queda claro el lugar de lo histórico o lo político y en la otredad leviniana se pasa de lo político a lo ético, dejando la puerta abierta para que ambos puedan seguir alimentando un discurso hegemónico. Esto es sintomático del reto constante que enfrentan los estudios transatlánticos, un eurocentrismo perdurable que críticos como Joseba Gabilondo han tratado de cuestionar en su acercamiento al Atlántico Hispano.

El trabajo de Joseba Gabilondo, que se evidencia fundamentalmente en su introducción a un volumen editado sobre el tema que aparece en 2001 (y que no se cita a menudo en otras disquisiciones transatlánticas), responde a la necesidad de replantearse la institucionalización del latinoamericanismo y el peninsularismo y la incapacidad de éstos de pensar lo global desde postulados que en última instancia no reviertan a lo nacional y terminen siendo nacionalistas. De ahí que movilice la categoría del Atlántico Hispano (Hispanic Atlantic) para unos estudios que son igualmente transatlánticos. En este sentido, Gabilondo plantea que, a partir de la globalización, hay que repensar no sólo la condición hispana contemporánea en ambos lados del Atlántico, sino que además hay que repensar la modernidad y la 
nación (estado), de tal manera que tanto la modernidad como el nacionalismo se convierten en un efecto imaginario de un sistema atlántico imperialista que comienza con el temprano expansionismo español y portugués y continúa con el imperialismo norteamericano contemporáneo. A su vez, y siguiendo el trabajo de Mignolo, Gabilondo plantea que la modernidad hay que pensarla en última instancia como una condición imperialista; el Atlántico es por lo tanto un espacio de imperialismos, donde la temprana modernidad y la globalización están genealógicamente conectados. Esta nueva rehistorización de lo geopolítico y lo biopolítico, a su vez, lleva a Gabilondo a cuestionar la raíz anglocéntrica de la propuesta más radical y productiva de lo atlántico, esto es, el trabajo de Gilroy que ya ha sido criticado por Simon Gikandi, entre otros. Gilroy excluye a África y Latinoamérica de su discurso, evidenciado la falta de diálogo que existe no sólo entre Gilroy y el Atlántico Hispano, sino entre el Atlántico Angloamericano y el Hispano. En este sentido, la propuesta de Gabilondo es netamente histórica y teórica, oponiéndose a propuestas posteóricas o derridianas donde la otredad al final vuelve a convertirse en fetiche teórico para reeuropeizar el discurso atlántico. En su trabajo más reciente, Gabilondo precisamente desmonta las nuevas tendencias críticas que parten de Derrida y Foucault para proponer la otredad y la biopolítica como discursos carentes de geopolítica, que terminan revirtiendo a la posición de recentrar el pensamiento filosófico europeo como universal (“A Multicultural Critique”). Su trabajo apunta a caminos que ameritan más exploración, como el releer lo geopolítico desde lo biopolítico para así conseguir mapas cognitivos tridimensionales del Atlántico. Por último, vale la pena mencionar el número especial editado por Jill Robbins y Roberta Johnson más recientemente, ya que el proyecto de las editoras, explicitado en su introducción, encuentra correspondencia segura con los trabajos que se reúnen en el dossier. A pesar de que es la España plurilingüe y pluricultural la que concierne a esta colección de ensayos, la perspectiva de sus organizadoras proviene de una modernidad transatlántica cuyos postulados han delineado teóricos latinoamericanos, como Dussel y Mignolo. El conjunto de ensayos verdaderamente descentra lo español en la literatura y cultura peninsulares, no sólo desde Latinoamérica sino desde las Islas Canarias, África y otros ángulos. ${ }^{23}$

Siguiendo estas exploraciones transatlánticas en sus diferentes vertientes, los ensayos de este volumen intentan conectar, relacionar espacios (físicos, emocionales, políticos, discursivos) aparentemente desligados a través de los tiempos para ofrecer otros recorridos a través del Atlántico. Sin embargo, somos conscientes de la ausencia de África en los proyectos que aquí presentamos, por lo que esperamos

${ }^{23}$ Consultar además la colección de ensayos de Benita Sampedro y Simon Doubleday que se ocupa de cuestionar las fronteras españolas haciendo hincapié en regiones ambivalentes y en disputa. 
que se concrete otra colección donde se explore rigurosamente la centralidad de África en el Atlántico Hispano, que continúe superando las líneas propuestas por Gilroy, no sólo en formulaciones nacionales o nacionalistas, en la historia de la plantación, el azúcar o la esclavitud, o en viajes unidireccionales hacia las Américas sino trianguladamente, en travesías de idas y vueltas. ${ }^{24}$

Considerando las diversas líneas teóricas apuntadas, tanto sobre el Atlántico como sobre su compleja espacialidad, nos resulta interesante cerrar esta reflexión con la analogía de un Atlántico demarcado por dos costas (este y oeste), similar a un texto entre dos tapas, relación que subraya Susan Stewart acerca del libro. Cerrado, el libro es un objeto material, concreto; pero una vez abierto, sus límites físicos se vuelven abstractos y establecen nexos a nuevas temporalidades (37). Tal como no existe acuerdo universal en cuanto a cómo definir los límites del Atlántico en las áreas de aguas abiertas, el desmoronamiento de límites y de superficies abre infinitas posibilidades de significados nuevos, y en este gesto se inserta la propuesta del presente volumen. El aporte de esta serie de meditaciones sobre el Atlántico, que incorporan nuevas reflexiones sobre el espacio y la geopolítica, permite transformar las cartografías del Atlántico, a través de sus metáforas de extensión y contención -que resisten fijarse en un punto-, y desplegar apenas un pequeño número de las múltiples otredades que lo habitan y surcan. En esta instancia, la triangulación es un mero recurso conceptual para abrir este espacio, pero no debe pensarse como un espacio estático, sino en constante fluir, en el que arbitrariamente hemos querido imponer a Latinoamérica como núcleo focal para desviar la mirada normativa que tan a menudo condiciona nuestra mirada inclusive hacia nosotros mismos.

\section{Propuestas tRiangulares PARA UNA CONFLUENCIA}

Este volumen se construye a partir de una serie de prácticas transatlánticas, apenas representativas de todo un campo de posibilidades, para problematizar y abrir las delimitaciones de estos estudios. La figura de la triangulación busca desmontar binomios y dualidades, complicar las idas y venidas, refractar las miradas y enfocarse en los aportes de Latinoamérica a un campo cuya amorfa elasticidad se resiste a definiciones fáciles. Las contribuciones individuales del volumen abarcan geográfica y cronológicamente un mapa amplio de reflexiones en torno a

\footnotetext{
${ }^{24}$ Hay un volumen de reciente aparición en Barcelona que explora la negritud en la España posfranquista, editado por Rosalía Cornejo Parriego. También hubo una conferencia el presente año en Ghana que agrupó a críticos del norte y del sur, de Europa, las Américas y África, para examinar precisamente el África Atlántica. En los últimos años, tanto historiadores como literatos norteamericanos han explorado abundantemente el Atlántico Negro. En el campo de estudios latinoamericanos, la crítica cultural y la historia se han ocupado del tema copiosamente, no sólo en el Caribe y Brasil, trazando así el camino para un tratamiento más abarcador de África dentro de este campo de estudio.
} 
textos y contextos, figuras y genealogías que se desplazan de los focos de análisis tradicionales y aceptan otros ángulos de lectura, sin perder de vista la centralidad de Latinoamérica y el campo de estudios latinoamericanos.

La primera sección se ocupa del período colonial, encabezada por el trabajo de Elvira Vilches que contribuye a la teorización del Atlántico Hispano al repensar las nociones de espacio y valor. Vilches propone una lectura alternativa de un Atlántico visto como vehículo administrativo para las redes coloniales de comunicación. Tomando como texto primario el paraje sobre las Azores en la Historia y el Sumario de Gonzalo Fernández de Oviedo, el artículo presenta el espacio atlántico no sólo como el contra-lugar del Mediterráneo, sino como un tercer espacio, según la formulación de Edward Soja que reelabora el trabajo de Henri Lefebvre. Este tercer espacio nace de la cesura entre un océano asociado a los archipiélagos atlánticos y la mar océana de las Indias; entre un Atlántico inteligible y uno inestable que hace vacilar la brújula y depreciar el valor de las cosas. Vilches explora prácticas supresoras en la producción europea del espacio y su relación con un desajuste de capital que hacen del Atlántico un continuum en tensión.

Lisa Voigt continúa la línea de cuestionamiento de las direcciones en que circula el capital, esta vez literario, entre los imperios ibéricos -Portugal y España-, África y Latinoamérica. Enfocándose en las narrativas de cautiverio y naufragios, Voigt traza una trayectoria de apropiaciones que sitúa la experiencia en las Américas como un discurso formal privilegiado que retorna transformado a Europa. Las figuras de Alvar Núñez Cabeza de Vaca, que se auto representa, y de Pedro Serrano, al que el Inca Garcilaso de la Vega rescata literariamente, sirven aquí para desmontar la mirada crítica tradicional que encasilla estos relatos como derivativos de modelos literarios europeos. Voigt explora los ecos de estos relatos en el Viejo Mundo, desde la novela de Miguel de Cervantes, Los trabajos de Persiles y Sigismunda, a un folleto portugués de João Carvalho Mascarenhas, Memorável Relaçam da Perda da Nao Conceiçam. Al posicionar a Latinoamérica como eje importante en las prácticas discursivas de una temprana modernidad transatlántica, se desdibujan tanto las fronteras genéricas (entre novela, relato o historia) como las territoriales (España y Portugal, Viejo y Nuevo Mundos).

La reflexión territorial es justamente el eje central del ensayo conjunto de Barbara Fuchs y Yolanda Martínez-San Miguel. A partir del poema épico La grandeza mexicana de Bernardo de Balbuena, Fuchs y Martínez-San Miguel posicionan la ciudad de México como bisagra entre Asia y Europa, destacando su condición de "metrópolis colonial” que compite con España. México no es aquí un lugar intermedio, periférico, de paso, sino otro centro en la medida en que controla el comercio del Pacífico y asigna un sistema de valores alternativos al tráfico de cuerpos, mercancías, artefactos e ideas. La hibridez de la Ciudad de México que 
Balbuena presenta implica un doble desafío para el poder hegemónico de Madrid, tanto económico como discursivo. Fuchs y Martínez-San Miguel demuestran cómo Balbuena desplaza el espacio del héroe épico por el de la urbe, que se convierte en el personaje principal de un discurso heroico mercantilista. Más allá de una lectura proto criollista que privilegia lo local, aquí se explora un México integrado de lleno en el comercio global.

El trabajo de Ralph Bauer hace que la América anglosajona dialogue con Latinoamérica y que Nuevo México y Nueva Inglaterra sean parte de unas prácticas científico-discursivas similares ante sus modelos europeos, aunque con diferentes resultados. Este análisis comparativo retoma la literatura que debate la aparición de los grandes cometas de finales del siglo xviI, en particular los que luego recibirían el nombre de Newton y Halley (1680/1681), y que sirven de plataforma de discusión tanto a Carlos de Sigüenza y Góngora como a Increase Mather. La doble controversia sobre el significado sobrenatural de estos cometas ofrece otras perspectivas para la historiografía de la incipiente "revolución científica" del siglo diecisiete. El ensayo plantea la relación triangular entre el saber criollo y los saberes indígena y europeo, no en el contexto de la idea del "progreso científico", sino en el contexto local del entramado político, social y religioso de ambos espacios coloniales.

El aporte significativo de estos trabajos en el área colonial es relativizar el espacio atlántico que se ha asumido tradicionalmente como fijo y definitivo, no sólo en su dimensión geopolítica sino también en su dimensión discursiva. El concepto de tercer espacio, el multifacético viaje transatlántico que usa el Nuevo Mundo como espacio de transformación, la apertura al Pacífico y a las posibilidades que ofrecen los estudios comparativos hemisférico/continentales exponen los aciertos y los obstáculos con que se enfrentan los estudios transatlánticos. Cuestionan tanto la geografía como la aplicación de modelos que pueden resultar ajenos a los discursos literario-críticos o a los diseños político-culturales latinoamericanos.

La segunda sección, arraigada fundamentalmente en la Latinoamérica del siglo xIX, se ocupa de producciones literarias locales y localizadas, en cierta forma cisatlánticas, que a la vez son frutos de desplazamientos físicos y discursivos y establecen diálogos tanto transatlánticos como transnacionales dentro del propio continente americano a lo largo de su etapa de consolidación nacional.

A partir de las teorías raciales angloamericanas, el ensayo de Ruth Hill retoma "La agricultura de la Zona Tórrida” y varios artículos periodísticos de Andrés Bello para rastrear la contribución del intelectual decimonónico a la formación racial latinoamericana. Al analizar la evolución del pensamiento del venezolano, Hill distingue dos etapas marcadas por su estadía en Londres y por su posicionamiento respecto del Atlántico. El primer transatlanticismo es más universal y comparte con muchos de sus contemporáneos un exotismo ideológico que está influido 
por el concepto biocultural de raza de Jeremy Bentham. Posteriormente, su transatlanticismo, sin embargo, hace un giro hacia lo hemisférico-continental que reduce la dinámica racial latinoamericana al binario rojo-blanco prevaleciente en Norteamérica. Al recalcar las contribuciones de Bello al debate político-cultural sobre el mestizaje y la raza, Hill destaca que la visión del intelectual proyectó la supresión del indígena y justificó la dominación económica y política “caucasiana” en Hispanoamérica.

Enfocándose en la narrativa de Frances Calderón de la Barca, el trabajo de Nina Gerassi-Navarro analiza las confluencias políticas y culturales entre Europa, Estados Unidos y México. La mirada de la viajera es producto de sus afiliaciones personales y de una trayectoria compleja que la lleva desde su Escocia natal a Nueva Inglaterra, y luego al tumultuoso México, en plena efervescencia nacionalista, como esposa del diplomático español Ángel Calderón de la Barca. Amiga y colaboradora del historiador William H. Prescott, recoge durante sus viajes por México información para el trabajo historiográfico de este último. Comparte además cierta afinidad con la estética paisajista norteamericana que intenta redefinir el continente americano, siguiendo el postulado político del "destino manifiesto". Simultáneamente, en su función de diplomática, Calderón defiende la cultura española como fuerza civilizadora y desconfía del excepcionalismo norteamericano. Desarticulando alianzas que se entrecruzan y se contradicen, Gerassi-Navarro lee La vida en México como un texto híbrido donde México emerge como el lugar que reconfigura diferentes posturas estéticas y políticas que se debatieron en el continente americano durante la posindependencia.

Erika Beckman presenta a José Asunción Silva y la Colombia finisecular en relación a Estados Unidos y a Europa. Recupera al Silva comerciante de artículos de lujo que termina en bancarrota y que escribe anuncios publicitarios para sus tiendas exhortando el consumo de objetos importados. Analizando la novela De sobremesa, Beckman hace hincapié en la convergencia estética del aviso publicitario y la literatura para exponer el doble discurso que Silva entreteje, donde lo bello no sólo es un objeto de consumo sino una propuesta estética del goce. Beckman demuestra cómo el protagonista de la novela de Silva no produce sino que sólo consume, creando así síntomas de desequilibrio económico, psicológico y sexual queél mismo relaciona con los desbarajustes del intercambio comercial transatlántico. De esta forma, De sobremesa ofrece una lectura alegórica de la inestabilidad fundamental que caracteriza el patrón importador/exportador, modelo que en última instancia pareciera haber asegurado el endeudamiento y la bancarrota figurativa y literal de los países latinoamericanos modernos.

Concentrándose en dos cuentos de Leopoldo Lugones, Juan Pablo Dabove analiza la triangulación equívoca que establece Argentina con Europa (particularmente 
Inglaterra y sus imaginarios coloniales en África y Asia). Dabove se enfoca en el modo en que Lugones transcultura el lenguaje gótico imperial para articular la ansiedad del letrado argentino frente a una modernidad inestable, emblematizada por las crisis económicas y por los "otros” amenazantes: el inmigrante y el indio. Los cuentos presentan dos caras de esa ansiedad, con el mono como representante de la otredad. En "Un fenómeno inexplicable”, la contaminación entre la civilización y la barbarie se da en el personaje de un inglés cuya sombra de mono confirma el retorno de lo reprimido colonial. En "Yzur", el mono (oriental y negro a la vez) se resiste a aprender la lección y revela la falla de la ciencia como saber. Lejos de exorcizar los monstruos, en Lugones el otro adquiere proporciones amenazantes que hacen que el letrado abandone su apropiación de los patrones narrativos del colonialismo inglés. De esta manera, Dabove expone los límites de un imaginario político argentino confrontado con sus propias nociones de modernidad.

Estos ensayos sobre el siglo xix, aparentemente en torno a una geografía local y una producción literaria individual, se erigen, sin embargo, como puntos focales para un diálogo que apela a redes transatlánticas y continentales. En particular, exponen la compleja armazón interna del continente americano, cuyos puntos de referencia se extienden más allá de Europa y, en sus procesos de reconfiguración nacional, se debaten entre modelos de modernidad y cosmopolitismo. Estas redes encuentran ecos en las propuestas de la tercera sección. Los últimos trabajos, de relevancia más contemporánea, exploran desvíos genealógicos y geográficos que buscan recolocar conceptos y categorías que, aunque se retomen a menudo en los estudios transatlánticos, resultan con frecuencia tangenciales a su vertiente hispánica o latinoamericana.

En primer lugar, Joseba Gabilondo rastrea la trayectoria histórica y las transformaciones discursivas del concepto de "raza latina" que permiten a pensadores latinoamericanos y españoles por igual hacer uso de él. Su formulación se origina a principios del siglo xix en Alemania, pasa al Atlántico hispano a mediados de ese mismo siglo y se hibrida con el discurso colonial hispano anterior de pureza de sangre, adquiriendo una flexibilidad ideológica que sirve como reacción a los postulados noreuropeos del discurso racial biológico. Gabilondo plantea que el discurso racial hispano es geopolítico y atlántico y que, por tanto, toda geografía atlántica es a la vez racial. Para principios del siglo xx, el discurso de raza latina se redefine en el Atlántico Hispano, ya que España y Latinoamérica se triangulan respecto a los Estados Unidos y a Europa, y se transforma en un discurso nacionalista (Día de la raza, hispanidad, etc.) que se debe seguir pensando desde lo atlántico. A través de esta genealogía, Gabilondo enfatiza que la flexibilidad ideológica del término da lugar a extensiones que, aunque parecen no ser raciales, se deben siempre analizar como usos de "raza" (la Raza de la cultura chicana, la transculturación e 
hibridación latinoamericanas, el excepcionalismo de la España neoliberal y global) que, por último, permiten replantearse la continuidad atlántica entre modernidad y globalización más allá del nacionalismo.

Tabea Linhard explora una "poética del naufragio" ligada a la "melancolía" a partir del tropo de la travesía marítima. Compara el cuento de Cristina Peri Rosi "La influencia de Edgar A. Poe en la poesía de Raimundo Arias” y la novela autobiográfica Castillos en la tierra de Angelina Muñiz-Huberman, conectándolos a su vez con las proposiciones teóricas del Atlántico negro de Gilroy a través de un cuadro de J. M. W. Turner (1840) y una fotografía de Idelfonso Serra (1992). Estas imágenes le sirven para evocar los cruces traumáticos tanto del barco lleno de esclavos como de las pateras de los inmigrantes africanos contemporáneos. Linhard subraya la sensación de pérdida irrecuperable que subyace en el corpus literario, en la medida en que la subjetividad de los personajes principales de los textos analizados está anclada en un naufragio. A través de la reconstrucción de la infancia interrumpida por el exilio de estos personajes, se apela a una memoria o cartografía espectral que remite siempre a otras travesías. Esta pérdida no lleva a una parálisis teórica sino a una reconceptualización de la melancolía como factor determinante de esta poética del naufragio dentro de los estudios transatlánticos.

La noción de "compromiso político" es la preocupación central del ensayo de Luis Madureira. Partiendo de los juegos de autorreferencialidad en El año de la muerte de Ricardo Reis de José Saramago, Madureira se enfoca en un entramado de cruces entre la política y la literatura en el mundo lusohispánico para demostrar cómo se subvierte la mitología nacional portuguesa en torno a la apropiación neoimperial y autoritaria del Atlántico. Madureira explora la mirada revisionista de Saramago que recupera el "imperialismo espiritual” de Fernando Pessoa para una visión política transformadora de la que el Pablo Neruda de "La lámpara marina” es un artífice poético fundamental, aunque no el único. Pone a dialogar discursos políticos del dictador Salazar, ensayos de Paul Valéry, declaraciones de Jorge Amado y César Vallejo, y los hace confluir en la obra de Saramago que ofrece nuevas lecturas de la historia. A través de Saramago y de Neruda, Madureira explora otro Atlántico, orientado hacia el sur, y coloca a Latinoamérica como protagonista de una concepción solidaria internacional de la que los pueblos de la península ibérica serían partícipes.

A través de una relectura de la "épica”, Eyda M. Merediz explora las alianzas interinsulares entre Cuba y las Islas Canarias y su particular relación con España a lo largo de los siglos. Analiza dos textos coloniales, Espejo de Paciencia de Silvestre de Balboa (1608) y Antigüedades de las Islas Afortunadas (1604) de Antonio de Viana, y una épica cinematográfica moderna, Mambí(1998), de Teodoro y Santiago Ríos. Desde una perspectiva transhistórica y transatlántica, explora 
los espacios territoriales de estas islas que conducen a una noción fluida de lo nacional, según se evidencia en lo que constituye su corpus fundacional. Merediz desvela los subterfugios presentes en los textos, que parecen construir mitologías locales/nacionales pero que, sin embargo, terminan por alimentar nexos coloniales. Son los mismos nexos, ahora neocoloniales, los que se corroboran en la revisión contemporánea del pasado en la película Mambí. Este patrón que se repite lleva a Merediz a reflexionar sobre itinerarios crítico-teóricos recientes y a ofrecer una advertencia sobre la persistencia de dispositivos ideológicos que perpetúan la condición de colonialidad.

Esta reflexión sobre los estudios transatlánticos y los retos del Atlántico Hispano sirve de colofón no sólo al último ensayo sino al volumen en general, que, a través de la figura de la triangulación, añade otras dimensiones al debate. Los ensayos que aquí se presentan son evidencia de que los estudios transatlánticos no necesariamente proponen una metodología nueva o innovadora ausente en otros campos de investigación. En todo caso, proponen recuperar espacios marginados, relaciones excluidas e incluso desfamiliarizar el ángulo de estudio. El hecho de que el Atlántico se mire teóricamente en función de la circulación multidireccional de textos, artefactos e ideas, no impide que en la praxis se continúen perpetuando prácticas críticas cuestionables, como ignorar la fluctuación de las nociones de valor, diluir las relaciones de poder, no trascender una geografía limitante, y no interrogar el lugar desde donde se enuncia o se mira aunque las miradas se refracten en distintas direcciones. Si bien para unos los estudios transatlánticos han estimulado valoraciones comparativas en los estudios imperiales, hemisféricos e ibéricos, en otros han generado una reacción negativa, ya que los consideran una forma más de colonización de los estudios latinoamericanos al responder a modelos que se fraguan en Norteamérica o Europa. Sin embargo, los acercamientos transatlánticos que aquí presentamos no buscan obviar la ecuación colonial a priori ni promover una visión totalizadora, homogénea del Atlántico. Apostar por los proyectos de colaboración, por la suma de saberes, por la reconfiguración de las áreas de estudio son maneras fructíferas de dialogar, en tanto no se reduzca a Latinoamérica y su contribución teórica (tal como se ha hecho con África) a una pieza menor en otro proyecto eurocéntrico o del Atlántico Norte que la excluya, esquive, reinscriba o engolfe, escudándose en las dinámicas de la globalización.

\section{BiBLIOGRAFÍA}

Adorno, Rolena. "Nuevas perspectivas en los estudios literarios coloniales hispanoamericanos". Revista de crítica literaria latinoamericana 14/28 (1988): 11-27. 
"Reconsidering Colonial Discourse for Sixteenth-and-Seventeenth-Century Spanish America”. Latin American Research Review 28 (1993): 134-45.

Alencastro, Luis Felipe de. O Trato dos Viventes. Formação do Brasil no Atlântico Sul, séculos XVI e XVII. São Paulo: Companhia das Letras, 2000.

Anuario de Estudios Atlánticos. Dialnet. 25 agosto $2007<$ http://dialnet.unirioja. es/servlet/revista?tipo_busqueda=CODIGO\&clave_revista=5528 $>$.

Arias, Santa y Mariselle Meléndez, eds. Mapping Colonial Spanish America. Places and Commonplaces of Identity, Culture and Experience. Lewisburg: Bucknell UP, 2002.

Armitage, David. “Tres conceptos de historia atlántica”. Revista de Occidente 282 (2004): 7-28.

Bailyn, Bernard. Atlantic History: Concepts and Contours. Cambridge: Harvard UP, 2005.

Bauer, Ralph. “The Question of the Third Term: Coloniality and Comparative Early American Studies”. Lisa Voigt y Eric Slaugther, eds. Incomparable Americas: Colonial American Studies after the Hemispheric Turn. En prensa.

Bermúdez, Silvia. "La Habana para un exiliado gallego: Manuel Curros Enríquez, La Terra Gallega y la modernidad nacional transatlántica”. Modern Language Notes 117/2 (2002): 331-42.

"Rocking the Boat: The Black Atlantic in Spanish Pop Music from the 1980s and the 90s”. The Arizona Journal of Cultural Studies 5 (2001): 177-93.

Beverley, John y José Oviedo. The Postmodernism Debate in Latin America. Michael Aronna, trad. Durham: Duke UP, 1995.

Boxer, Charles R. The Portuguese Seaborne Empire, 1415-1825. Nueva York: A. A. Knopf, 1969.

Braudel, Fernand. El Mediterráneo y el mundo mediterráneo en la época de Felipe II [1949]. 2 vols. Mario Monteforte Toledo y Wenceslao Roces, trad. MéxicoBuenos Aires: FCE, 1953.

Buchenau, Barbara y Marietta Messmer. “An Introduction to Intercultural Negotiations in the Americas and Beyond”. Comparative Literature and Culture: A Web Journal 3/2 (2001). 3 agosto de $2007<$ http://clcwebjournal. lib.purdue.edu/clcweb01-2/introduction01-2.html>.

Campa, Román de la. Latinamericanism. Minneapolis: U of Minnesota P, 1999.

Canny, Nicholas y Anthony Pagden, eds. Colonial Identity in the Atlantic World, 1500-1800. Princeton: Princeton UP, 1989.

Castillón, Catalina, Cristián Santibáñez y Marc Zimmerman, eds. Estudios culturales y cuestiones globales: Latinoamérica en la coyuntura transnacional. Santiago: Bravo y Allende Editores/LA CASA, 2005. 
Castro-Gómez, Santiago y Eduardo Mendieta. Teorías sin disciplina. Latinoamericanismo, poscolonialidad y globalización en debate. México: Porrúa, 1998.

Cañizares Esguerra, Jorge. How to Write the History of the New World: Histories, Epistemologies, and Identities in the Eighteenth-Century Atlantic World. Stanford: Stanford UP, 2001.

Puritan Conquistadors: Iberianizing the Atlantic, 1550-1700. Stanford: Stanford UP, 2006.

y Erik Seeman, eds. The Atlantic in Global History. Nueva York: Prentice Hall, 2006.

Certeau, Michel de. The Practice of Everyday Life. Steven Rendall, trad. Berkeley: U of California P, 1984.

Chaunu, Huguette, Pierre Chaunu y Guy Arbellot. Séville et l'Atlantique, 15041650. París: A. Colin, 1955.

Chaunu, Pierre. Les Philippines et le Pacifique des Ibériques (XVIe, XVIIe, XVIIIe siècles). París: Ecole Pratique des Hautes Etudes, 1960.

Clifford, James. “Traveling Cultures”. Cultural Studies. Lawrence Grossberg, Cary Nelson y Paula A. Treichler, eds. Londres: Routledge, 1992. 96-116.

Cornejo Parriego, Rosalía, ed. Memoria colonial e inmigración: la negritud en la España posfranquista. Juan Goytisolo, prol. Barcelona: Ediciones Bellaterra, 2007.

Derrida, Jacques. Of Grammatology. Gayatri Chakravorty Spivak, trad. y prol. Baltimore y Londres: The Johns Hopkins UP, 1976.

Dussel, Enrique. "Beyond Eurocentrism: The World-System and the Limits of Modernity”. The Cultures of Globalization. Fredric Jameson y Masao Miyoshi, eds. Durham: Duke UP, 1998. 3-31.

El encubrimiento del Otro. Hacia el origen del mito de la modernidad. Quito: Ediciones ABYA-YALA, 1994.

The Invention of America. Eclipse of "the Other" and the Myth of Modernity. Michael D. Barber, trad. Nueva York: Continuum, 1995.

Elliott, John H. Empires of the Atlantic World: Britain and Spain in America 14921830. New Haven: Yale UP, 2006.

En búsqueda de la historia atlántica. Las Palmas: Cabildo Insular de Gran Canaria, 2001.

Encyclopaedia Britannica (EB). 25 agosto 2007. <http://www.britannica.com/>.

Faber, Sebastiaan. Exile and Cultural Hegemony: Spanish Intellectuals in Mexico (1939-1975). Nashville: Vanderbilt UP, 2002.

Fernández Armesto, Felipe. Before Columbus: Exploration and Colonization from the Mediterranean to the Atlantic, 1229-1492. Filadelfia: U of Pennsylvania P, 1987. 
The Canary Islands after the Conquest. The Making of a Colonial Society in the Early Sixteenth Century. Oxford: Clarendon, 1982.

Las Islas Canarias después de la conquista. La creación de una Sociedad Colonial a principios del siglo XVI. Las Palmas: Ediciones del Cabildo Insular de Gran Canaria, 1997.

Fernández deAlba, Francisco y Pedro Pérez del Solar. “Hacia un acercamiento cultural a la literatura hispano-americana”. "Dossier: Transatlántica: Idas y vueltas de la literatura y cultura hispano-americana en el siglo XX”. Iberoamericana. América Latina, España y Portugal: Ensayos sobre letras, historia y sociedad 6/21 (2006): 99-107.

Fiddian, Robin, ed. Postcolonial Perspectives on the Cultures of Latin America and Lusophone Africa. Liverpool: Liverpool UP, 2000.

Fonseca, Luís Adão da. "Prologue: The Discovery of Atlantic Space”. Portugal, the Pathfinder. Journeys from the Medieval toward the Modern World 1300ca. 1600. George D. Winius, ed. Madison: Hispanic Seminary of Medieval Studies, 1995. 5-17.

Foucault, Michel. “Of Other Spaces”. Diacritics 16 (1986): 22-27.

Frank, André Gunder. ReOrient: Global Economy in the Asian Age. Berkeley: U of California P, 1998.

Fuchs, Barbara. “Imperium Studies: Theorizing Early Modern Expansion”. Postcolonial Moves: Medieval through Modern. Patricia Clare Ingham y Michelle R. Warren, eds. Nueva York: Palgrave, 2003. 71-90.

Gabbacia, Donna. “A Long Atlantic in a Wider World”. Atlantic Studies: Literary, Cultural, and Historical Perspectives 1.1 (2004): 1-27.

Gabilondo, Joseba. “A Multicultural Atlantic Critique of European Universalism: Neonationalism from Derrida to Agamben”. Tropos 31 (2005): 8-53.

“Introduction. Special Section: The Hispanic Atlantic”. The Arizona Journal of Cultural Studies 5 (2001): 91-113.

García Canclini, Néstor. Culturas híbridas. Estrategias para entrar y salir de la modernidad. México: Grijalbo, 1989.

Gikandi, Simon. "In the Shadow of Hegel: Cultural Theory in the Age of Displacement”. Research in African Literatures 27/2 (1996): 139-150.

Gilroy, Paul. The BlackAtlantic. Modernity and Double Consciousness. Cambridge: Harvard UP, 1993.

Jáuregui, Carlos A. y Mabel Moraña. “Introducción”. Colonialidad y crítica en América Latina. Bases para un debate. Carlos A. Jáuregui y Mabel Moraña, eds. Puebla: Universidad de las Américas Puebla, 2007.

Klor deAlva, Jorge. “Colonialism and Postcolonialism as (Latin)American Mirages”. Colonial Latin American Review 1/2 (1992): 3-23. 
Kostroun, Daniella y Lisa Vollendorf, eds. Women and Religion in the Atlantic World (1600-1800). Toronto: U of Toronto P, 2009.

Lefebvre, Henri. The Production of Space [1974]. Donald Nicholson Smith, trad. Oxford: Blackwell, 1991.

Lucena Giraldo, Manuel. “La constitución atlántica de España y sus Indias”. Revista de Occidente 282 (2004): 29-44.

Lund, Joshua. "Barbarian Theorizing and the Limits of Latin American Exceptionalism”. Cultural Critique 47 (2001): 54-90.

Macpherson, Heidi S. y Will Kaufman, eds. New Perspectives in Transatlantic Studies. Lanham: UP of America, 2002.

Transatlantic Studies. Lanham: UP of America, 2000.

Martí-Olivella, Jaume. "Cuba and Spanish Cinema’s Transatlantic Gaze”. The Arizona Journal of Cultural Studies 5 (2001): 161-176.

Martínez-San Miguel, Yolanda. "Colonial No More: Reading Sor Juana from a Transatlantic Perspective”. Approaches to Teaching Sor Juana. Emilie Bergmann y Stacey Schlau, eds. Nueva York: MLA, 2007.

From Lackto Excess: 'Minor'Readings of LatinAmerican Colonial Discourse. Lewisburg: Bucknell UP, 2008.

Massey, Doreen. For Space. Londres: Sage Publication, 2005. Space, Place, and Gender. Minneapolis: U of Minnesota P, 1994.

Mauro, Frédéric. Le Brésil et l'Atlantique au XVIIIe siècle (1570-1670) [1960]. Paris: Société d'édition d'enseignement supérieur, 1977.

McClennen, Sophia A. "Inter-American Studies or Imperial American Studies?" Comparative American Studies 3/4 (2005): 393-413.

Mignolo, Walter. "Colonial and Postcolonial Discourse: Cultural Critique or Academic Colonialism?” Latin American Research Review 28/3 (1993): 120-132.

The Darker Side of the Renaissance. Literacy, Territoriality, and Colonization. Ann Arbor: The U of Michigan P, 1995.

"Globalization, Civilization Processes, and the Relocation of Languages and Cultures”. The Cultures of Globalization. Fredric Jameson y Masao Miyoshi, eds. Durham: Duke UP, 1998. 32-53.

Local Histories/Global Designs. Princeton: Princeton UP, 2000.

Moraña, Mabel, ed. The Ideologies of Hispanism. Nashville: Vanderbilt UP, 2005.

"Latin American Cultural Studies: When, Where, Why?” Debating Hispanic Studies: Reflections on Our Disciplines. Luis Martín-Estudillo, Francisco Ocampo y Nicholas Spadaccini, eds. Hispanic Issues On Line 1/1 (2006): 31- 
36. 3 agosto $2007<$ http://spanport.cla.umn.edu/publications/HispanicIssues/ hispanicissues-online/hispanic\%20issues\%20online-1.htm/morana.pdf>.

Morelli, Federica y Alejandro E. Gómez. "La nueva Historia Atlántica: un asunto de escalas”. Nuevo Mundo. Mundos Nuevos 6 (2006) [puesto en línea el 5 de abril de 2006, referencia del 1 de mayo de 2007] 3 agosto $2007<$ http:// nuevomundo.revues.org/document2102.html>.

O’Gorman, Edmundo. Historia de las divisiones territoriales de México [1937]. México: Porrúa, 1968.

La idea del descubrimiento de América. Historia de esa interpretación y crítica de sus fundamentos [1951]. México: Universidad Nacional Autónoma de México, 1976.

La invención de América. El universalismo de la cultura de Occidente [1958]. México: FCE, 2003.

O’Reilly, William. “Genealogies of Atlantic History”. Atlantic Studies 1/1 (2004): 66-84.

Ortega, Julio. “Post-theory and Transatlantic Studies”. Literary Research/Recherches Littéraires 37-38 (2002): 11-20.

"Post-teoría y estudios transatlánticos". Iberoamericana. América Latina, España y Portugal. Ensayos sobre letras, historia y sociedad 3/9 (2003): 109-17.

"Presentación. Dossier. Travesías cruzadas: hacia la lectura transatlántica". Iberoamericana. América Latina, España y Portugal. Ensayos sobre letras, historia y sociedad 3/9 (2003): 105-08.

"The Trans-Atlantic Project”. The Department of Hispanic Studies, Brown University. 20 mayo 2007 <www.brown.edu/Departments/Hispanic_studies/ transatlantic_project/index.html $>$.

Pérez de Mendiola, Marina. Introduction. Going Transatlantic: Toward an Ethics of Dialogue. Special Issue 3. Tempe, AZ: Chasqui; revista de Literatura Latinoamericana, 2005. 3-10.

Portillo Valdés, José María. Crisis atlántica. Autonomía e independencia en la crisis de la monarquía hispana. Madrid: Marcial Pons, 2006.

Pratt, Mary Louise. Imperial Eyes. Travel Writing and Transculturation. Nueva York: Routledge, 1992.

Quijano,Aníbal. “Coloniality of Power, Eurocentrism, and Latin America”. Nepantla 1/3 (2000): 533-80.

Rama, Ángel. La ciudad letrada. Hanover: Ediciones del Norte, 1984.

Real Academia Española (RAE). 25 Agosto 2007. <http://www.rae.es/>.

Rediker, Marcus. Between the Devil and the Deep Blue Sea: Merchant Seamen, Pirates and the Anglo-American Maritime World, 1700-1750. Cambridge: Cambridge UP, 1989. 
Roach, Joseph. Cities of the Dead: Circum-Atlantic Performance. Nueva York: Columbia UP, 1996.

Robbins, Jill y Roberta Johnson. "Introduction. Special Issue: Rethinking Spain from Across the Seas". Studies in 20th and 21st Century Literature 30/1 (2006): 9-19.

Rumeu de Armas, Antonio. España en el África Atlántica [1956]. 2da. ed. 2 vols. Las Palmas: Ediciones del Cabildo Insular de Gran Canaria, 1996.

Piraterías y ataques navales contra las Islas Canarias. 3 vols. Madrid: CSIC, Instituto Jerónimo Zurita, 1947-50.

Said, Edward. Culture and Imperialism. Nueva York: Alfred Knopf, 1993. Orientalism [1978]. Nueva York: Vintage Books, 1979.

Sampedro, Benita y Simon Doubleday, eds. Borders Interrogations: Questioning of Spanish Frontiers. Oxford y Nueva York: Berghahn Books, 2008.

Sarto, Ana del, Alicia Ríos y Abril Trigo. The Latin American Cultural Studies Reader. Durham: Duke UP, 2005.

Schwartz, Stuart B., ed. "Tropical Babylons” Sugar and the Making of the Atlantic World, 1450-1680. Chapel Hill: U of North Carolina P, 2003.

Seed, Patricia. "Colonial and Postcolonial Discourse". Latin American Research Review 3 (1991): 181-200.

Soja, Edward. Postmodern Geographies: The Reassertion of Space in Critical Social Theory. Londres: Verso, 1989.

Third Space. Journeys to Los Angeles and Other Real-and-Imagined Places. Malden y Oxford: Blackwell, 1996.

Steele, Ian K. "Bernard Bailyn's American Atlantic". History and Theory 46/1 (2007): 48-58.

Stewart, Susan. On Longing. Narratives of the Miniature, the Gigantic, the Souvenir, the Collection. Durham y Londres: Duke UP, 1993.

Toro, Alfonso del y Fernando del Toro, eds. El debate de la poscolonialidad en Latinoamérica. Una posmodernidad periférica o cambio de paradigma en el pensamiento latinoamericano. Frankfurt/Madrid: Iberoamericana/Vervuert, 1999.

Valladares, Rafael. “No sólo Atlántico. Portugal y su imperio”. Revista de Occidente 282 (2004): 45-58.

Verlinden, Charles. The Beginnings of Modern Colonization. Eleven Essays with an Introduction. Yvonne Freccero, trad. Ithaca: Cornell UP, 1970.

Vidal, Hernán. "The Concept of Colonial and Postcolonial Discourse. A Perspective from Literary Criticism”. Latin American Research Review 3 (1993): 11219. 
Wallerstein, Immanuel. Geopolitics and Geoculture. Essays on the changing WorldSystem. Cambridge: Cambridge UP, 1994.

El moderno sistema mundial. La agricultura capitalista y los orígenes de la economía-mundo europea en el siglo XVI. México: Siglo XXI, 1979. 